\title{
Astro Navigation Remembered
}

\author{
Catherine Hohenkerk, John Kemp and Brian Nibbs
}

(E-mail: prof.kemp@talk21.com)

\begin{abstract}
The authors give a personal account of the use of astro navigation during the years before GPS became the primary aid for oceanic navigation. The paper also contains an account of the support provided by The Nautical Almanac (NA) together with its associated tables and computer programs which ease the tedium of sight reduction while leaving the satisfaction to be found in successful astro observations at sea.

An early version of Section 2 of this paper formed part of a presentation made at the Symposium After Longitude-Modern Navigation in Context which took place at the UK National Maritime Museum from 22-23 March 2012.
\end{abstract}

\section{KEY WORDS}
1. Astro Navigation.
2. Almanacs.
3. Sextants.
4. NavPac.

First published online: 23 March 2012.

1. INTRODUCTION. This paper is simply a record of the way some of us used and thought about astro navigation at a time when, apart from Dead Reckoning (DR), it was the only worldwide system of oceanic navigation. As practised by mariners, astro navigation has the disadvantages that it needs a well-defined sea horizon and a sky with less than ten tenths cloud cover. It has the important advantage, as noted by Sir Francis Chichester, that it is not controlled by a political organisation. He might have added that it is also highly resistant to jamming or spoofing, to which GNSS (Global Navigation Satellite Systems) are highly vulnerable.

In the days before electronic calculators and computers, a navigator needed a sextant, a chronometer, a current almanac and a set of comprehensive trigonometric tables. The latter, together with a sextant were his personal property, taken from ship to ship. The chronometer and almanac were provided by the shipowner.

Sections 2 and 3 are intended to give a feeling for the mindsets of two of those navigators for whom, during the 1950s and 1960s, astro was a part of their daily routine. The production of The Nautical Almanac (NA) and the introduction of tables and software to reduce the tedium of attacking spherical trigonometry by manual methods is described at Section 4 by one of those directly involved.

\section{JOHN KEMP.}

2.1. Routines. Most of my astro navigation experience was in the North and South Atlantic. Weather was a primary problem North or South of about $40^{\circ}$ latitude so that, on a voyage from New York to Liverpool it could sometimes be overcast for the whole time, and observations had to be opportunistic rather than planned. 
This could mean trying to catch a glimpse of a clean 'limb' of the Sun through scudding clouds while attempting to stand upright in a gale and keeping one's sextant dry at the same time.

A successful observation under such conditions was a cause for self-congratulation and general relief. Lack of success might mean approaching a coast with only an approximate idea of one's position. This was especially fraught in poor visibility and, on one memorable occasion a position, misjudged by 25 miles, caused our ship to steam into Bantry Bay while under the impression that we were feeling our way eastwards along the south coast of Ireland (Kemp et al., 2008, Section 8.2).

Weather permitting, the standard procedure was to observe the Sun in the morning when it was bearing eastwards and then transfer the resulting position line to local noon so it made an effective cross with the latitude obtained from a Meridian Altitude (Mer Alt) observation.

Because of uncertainties in estimating the course and distance made good between the two observations, this procedure did not provide a particularly accurate fix. Nevertheless, the noon position was considered important because it formed the basis for calculating the ship's day's run, which was then entered in the deck and engine room logs and compared with the propeller revolutions to calculate the slip.

More precise positions could be calculated from star sights, taken at twilight in the morning or evening when both the stars and the sea horizon could be observed together. In practice, these were generally observed by the Chief Officer during his 0400-0800 watch, ideally comprising the altitudes of four stars with bearings spaced at about ninety degree intervals.

During daylight, with clear skies, the Sun was always available but, of course, at any one time an observation could only yield a single position line. Depending upon the stage of the lunar cycle, the Moon could sometimes also be observed on a bearing such that the resultant position line would make a satisfactory cross with a Sun position line.

In practice, the calculations associated with a Moon sight are no more difficult than for a Sun sight but there was an irrational suspicion of Moon observations. This might have been because the Moon was known to move more rapidly and more erratically than the Sun against the background of fixed stars, but it was probably also due to some additional corrections (negligible for the Sun) that are required to convert the observed altitude of the Moon to the true altitude. These include 'Parallax in Altitude' and 'Augmentation of the Moon's semi-diameter'. They were straightforward to apply but, for many, their causes were only half remembered from nautical school days and thus the subject of distrust and suspicion. The distrust of the Moon was probably due, at least in part, to Squire Thornton Stratford Lecky whose 1881 book, Wrinkles in Practical Navigation, many editions later (Lecky and Allingham, 1920) remained a kind of bible for most of my contemporaries. Lecky made his views clear at the outset: "Those (methods) founded on observations of the Moon are purposely omitted... . They require so many petty and vexatious corrections which spin the calculations out to a weary length...."

Not being a believer in what some called "The Gospel according to St Lecky", I can remember, as a keen young 3rd mate, obtaining simultaneous observations of the Sun and the Moon at about 0900 during a morning watch, and plotting the result proudly on the chart. Shortly afterwards, the Master came onto the bridge. 
"Why have you marked a fix on the chart rather than just a position line?" he demanded.

I explained that I had taken a sight of the Moon as well as the Sun, at which his response was, "Hrrmph!" as he turned to stalk off the bridge.

Rightly or wrongly, I interpreted this to mean 'You young blighters are too clever by half. I'll have to watch you like a hawk or you'll run my ship aground.'

2.2. Marcq St. Hilaire v. Longitude by Chronometer. At that time, there was some controversy as to whether one should use the 'Longitude by Chronometer' or the 'Marcq St Hilaire' (intercept) method for reducing observations.

The Longitude by Chronometer method comprises the assumption of a latitude and thence the calculation of the longitude at which the position line (at right angles to the bearing of the Sun or star) crosses that latitude.

The Marcq St Hilaire method begins with the assumption of a latitude and longitude and thence calculating the altitude of the Sun or star that would have been observed at that position. The difference between the observed and calculated altitude is the 'intercept' which can be laid off on a chart or a plotting sheet from the assumed position to arrive at a point through which the position line is drawn (again at right angles to the bearing of the Sun or star).

The two methods produce exactly the same position line but, among my colleagues, the Marcq St Hilaire method was considered the best and the most modern although it had been developed in 1875. As a young man, I had a certain contrariness in my nature (I probably still have, for that matter) so I decided that the Marcq St Hilaire method was the most fashionable rather than the most useful. I adopted the Longitude by Chronometer method for my Sun sights on the grounds that the calculation immediately identified a position through which to draw a position line. This, I felt, was superior to Marcq St Hilaire's procedure whereby the calculation only produced an intercept which then had to be used in a further stage of plotting before a position could be identified through which to draw a position line (see Figure 1).

Of course, when making multiple star observations, one had to construct a plot whichever method was used but, even then, I would often determine latitude by an observation of Polaris and use that to find the other position lines by the Longitude by Chronometer method. Plotting was still necessary to find a most probable position but it was simpler in that it did not require the laying off of intercepts (see Figures $2 \mathrm{a}$ and $2 b)$.

Estimating the most probable position was done on no scientific basis whatsoever by marking a hopeful pencilled dot within the nest of plotted position lines and giving it credibility by drawing a circle around it (not shown in Figures $2 \mathrm{a}$ and $2 \mathrm{~b}$ ). However, depending on the conditions at the time of an observation and the size of the cocked hats, we had what was probably a reliable feeling for the accuracy of the position; within a mile under ideal conditions, we thought, but much less with a poor horizon and oversized cocked hats etc.

Having said all that, it is certainly the case that the Marcq St Hilaire method has many advantages. Importantly, it is universal, in that it can be used for all observations, even those where the chosen body is close to the observer's meridian, when Longitude by Chronometer breaks down. It also lends itself to the use of short method tables or calculators which conveniently reduce the time needed for processing an observation. Being contrary can be a satisfying stance for a young man, but it is not always the most sensible. 


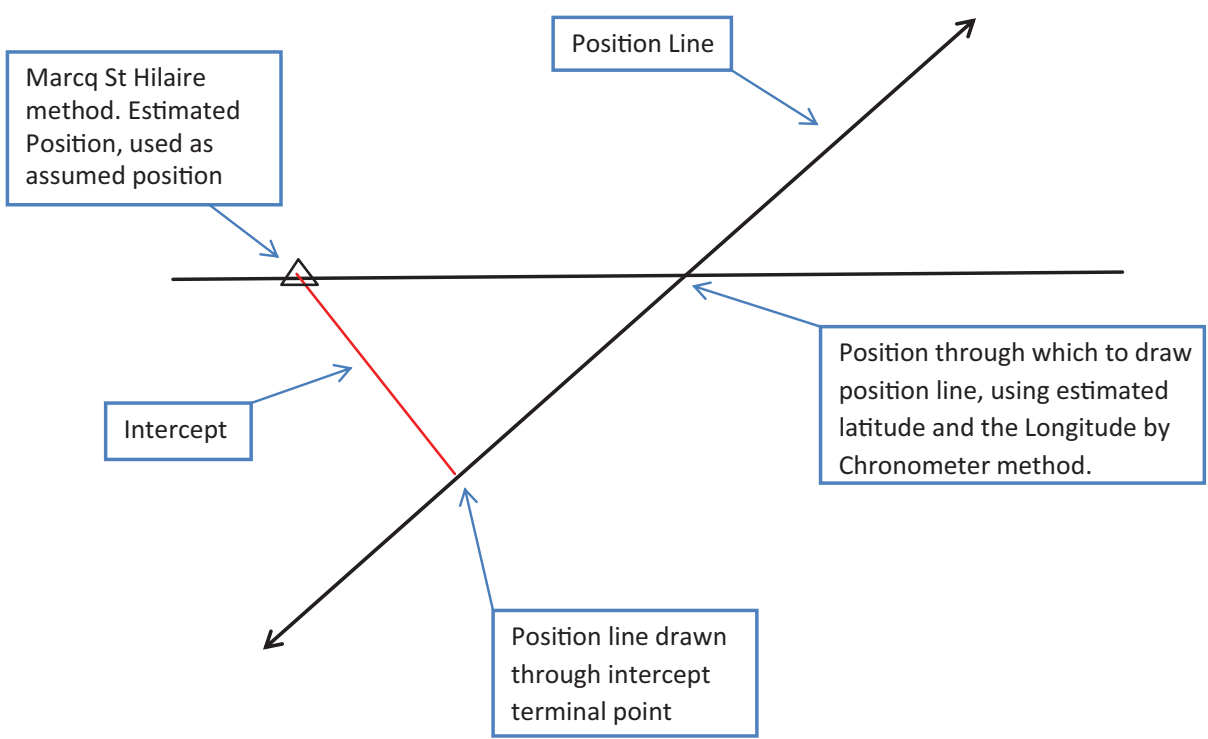

Figure 1. Finding a position line by Marcq St Hilaire and Longitude by Chronometer methods.

2.3. Equipment. The basic equipment we used for astro navigation was a sextant, a chronometer, a copy of the NA, tables, a chart (or plotting sheet) and parallel rulers.

The sextant was our own personal property. I acquired mine from a newly appointed shipmaster who, perhaps optimistically, decided that, with the normal team of competent officers under his command, he would have no further use for it. $\mathrm{He}$ charged me six pounds for what was, even in those days, a museum piece. No maker had sought fit to engrave his name on the instrument and I suspect it was one of a number that were produced in large numbers and anonymously during the First World War. It was fitted with a microscope and a vernier device for reading the inset silver scale as opposed to the modern (and much easier to read) micrometer devices fitted to the sextants used by all my colleagues. In due course, as I gained promotion, I reached a level of wealth such that I could have afforded a new micrometer sextant. However, by that time, I had become attached to my antique instrument and I never replaced it.

The chronometer was provided by the shipowner. It sat in gimballed state in a mahogany box with a glass lid in the chartroom. It was not expected that it would tell the time precisely, but it was expected that it would possess a near constant rate, either gaining or losing a second or two each day consistently throughout a voyage. Recording the chronometer error each day (using the Rugby or Washington radio signal), and winding the chronometer at the same time every morning was the responsibility of the 2 nd Mate, something that weighed heavily on me when I reached that exalted rank. It was not a problem when the ship was at sea and routine watches were established. However, in port, when watches were longer and less regular and when one went ashore rather than to one's bunk during off watch periods, it was all too easy to forget. Occasionally I allowed the chronometer to actually stop and it was then a challenge to wind and restart it, not so that it told the correct GMT, but so that it was running slow or fast by just the margin it would have had if its rate had been 


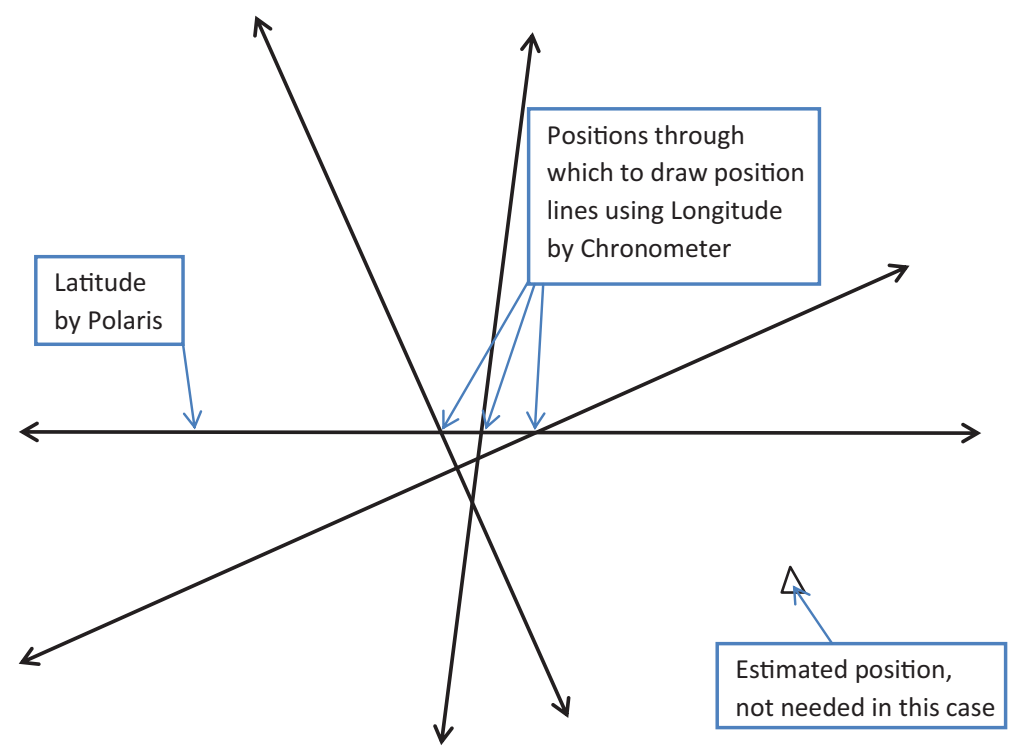

Figure 2a. Plotting four star position lines, Longitude by Chronometer method.

Marcq St Hilaire method. Position lines are drawn through intercept terminal points marked T

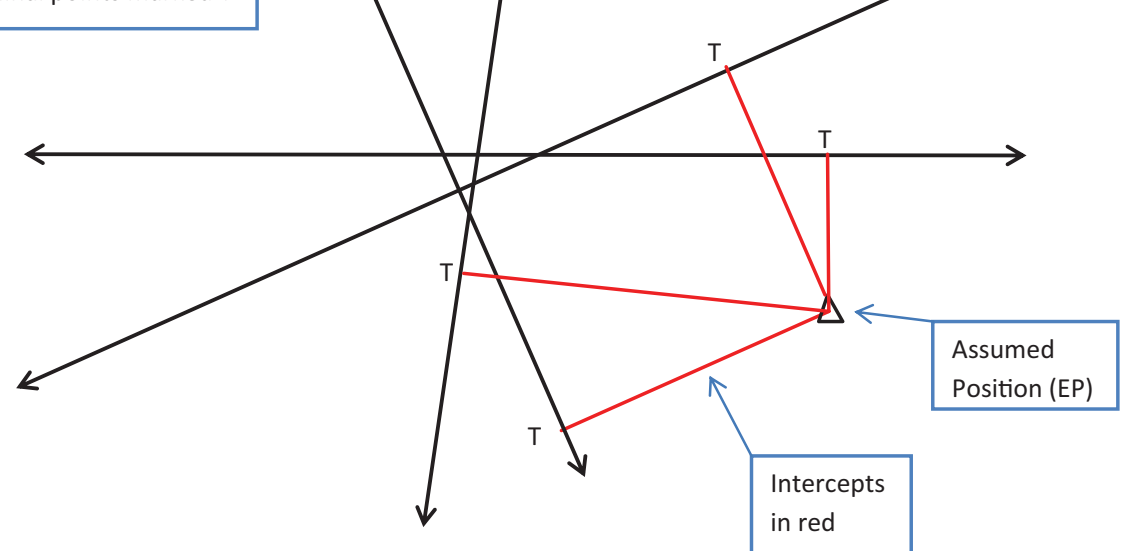

Figure 2b. Plotting the same four position lines, Marcq St Hiliare method.

constant since the last time check. Only thus would the chronometer book contain a record of consistent errors so that the Captain would not be moved to ask difficult questions. 
The parallel rulers were part of a ship's equipment, invariably of Captain Field's pattern and made of boxwood. The brass pivots on the older and much used rulers were worn and provided useful slack so that one could, when plotting, manipulate them slightly to achieve smaller cocked hats.

\section{BRIAN NIBBS.}

3.1. Routines. I went to sea some ten years after John, but the practice of navigation had changed little in that time. Radar was more reliable and more widely fitted but, offshore, astro navigation remained the only worldwide system for fixing a ship's position.

John served in tankers and cross-channel ferries. My service was in passenger liners, general cargo vessels and latterly cross channel ferries but, despite the time lapse and the different trade patterns, the navigation routines were very similar (see Figure 3).

My astro experience commenced during the last year of my apprenticeship with Ellerman Lines on-board the passenger liner City of Durban on the UK/South Africa run. Here I witnessed and formed a minor part of the daily rituals of morning and noon sights, my duty being to record the times for those officers participating in 'morning sights' by noting to the second, the chronometer times when the respective officers shouted "Now!" from the bridge wing.

Later, having eventually passed my 2 nd Mates Certificate, I admit to spending too many evenings at the 'Prospect of Whitby' and not enough in the study rooms of the Seamark Club; I clearly recall collecting my Certificate from Dock St E1 on the day I joined my first ship in West India Dock as 3rd Mate, the ageing steamship, City of Calcutta.

Having purchased his 'Husun' micrometer sextant a day or so previously, he was now armed with the main requisites of the astro navigator: a sextant, access to a chronometer and a volume of Norie's Tables (one was either a 'Norie's Tables' or a 'Burton's Tables' man) but no experience whatever of how to make responsible use of these facilities.

On my first evening on-board, having unpacked, I can remember opening the sextant box and putting my 2nd Mate's Certificate beside it - the black cover embossed with gold and my name in copperplate entered inside-and convincing myself that I had actually reached this stage of responsibility. Only two weeks previously I had signed off the coastal tanker Pass of Drumochter, on-board of which, all courses, steering commands and allied compass work were by the cardinal system in quarter points. I had served for three months as an uncertificated 2nd Mate, replenishing the coffers to allow me to re-take 2nd Mate's 'Orals'. These examinations were being regularly failed by a number of candidates due, in our opinion, to an examiner from Newcastle who seemed to dislike London students.

All Ellerman Line vessels had an astro navigation routine little different to that followed on John's tankers. The 2nd Mate (the nominated Navigating Officer) and the 3rd Mate took a morning sight, then worked out the 'run up' to noon. Prior to the estimated time of noon, the 2nd Mate returned to the bridge to join the 3rd Mate (the 0800-1200 watchkeeper) and 'the Old Man'(a term used respectfully for the Captain or Master); all three would observe the Mer Alt. From their respective calculated 


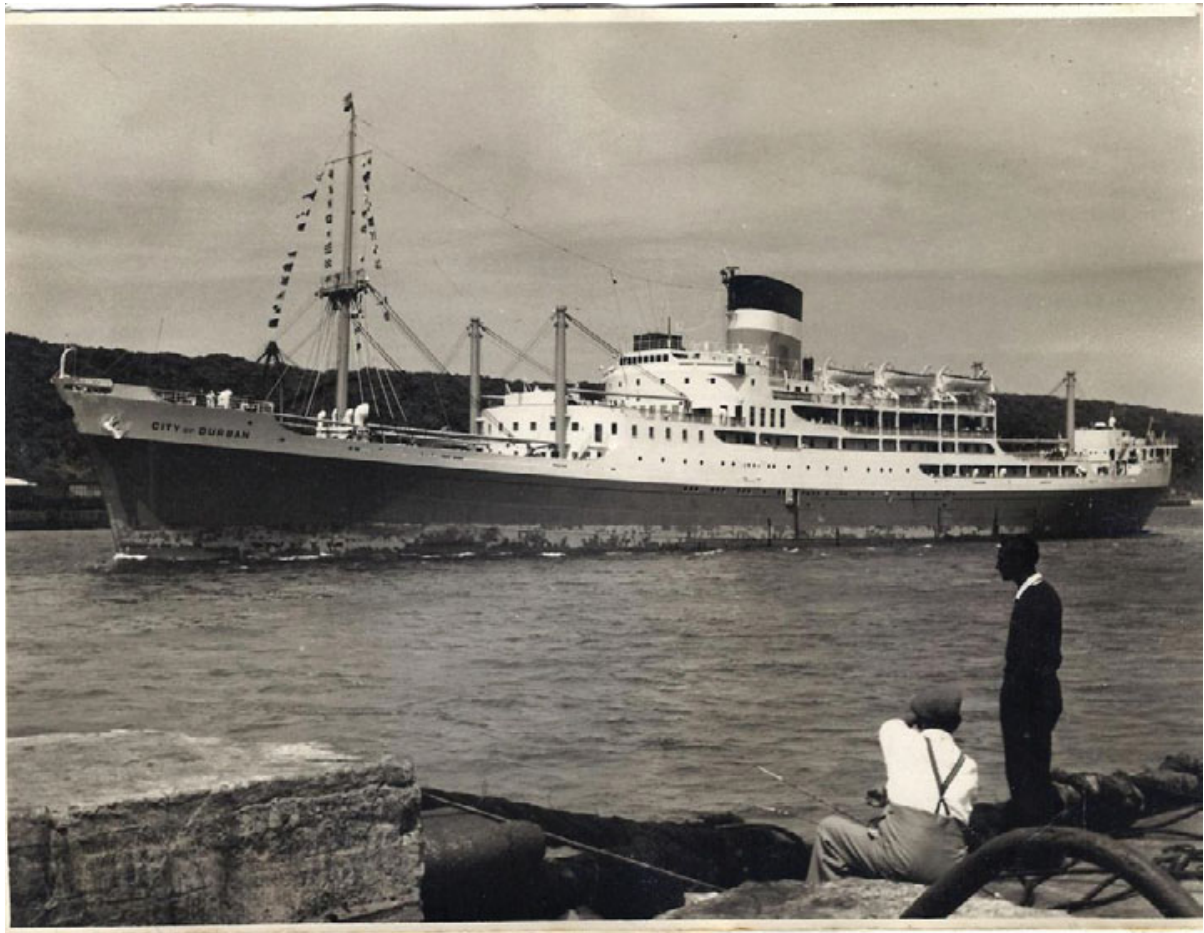

Figure 3. The City of Durban departing Durban, 1958.

positions, the 'Old Man' would declare the 'mean' position which was then used for the day's run, log entries and log abstracts (i.e. fuel consumed, slip etc).

The routine of long sea crossings, such as Panama to New Zealand and Suez to India (with the call at Aden for bunkers) did allow an unenviable routine to develop of morning sights, noon sights and, when promoted to Senior 2nd Mate on the Far East run and covering the traditional watch of the Mate (0400-0800), the pleasure of taking morning and evening star sights. This meant being absolved from the Sun/run/Sun ritual! Star sights, unlike morning/run up to noon sights, provided a 'fix' or, being truthful, a relatively small cocked hat.

Where John used logarithmic and trigonometric tables for a laborious and time consuming resolution of the astronomical 'PZX' triangle (see Section 4.2), I preferred to use the pre-computed altitudes for up to five stars listed in 'Sight Reduction Tables for Air Navigation [AP3270/Pub.No.249], Volume 1, Selected Stars, Epoch 1965.0' (HMSO, 1962); this tome is better known as AP 3270. It was published in the United States as Hydrographic Office Publication No. 249, the UK version being a facsimile reproduction (see also Section 4 ).

Use of these tables necessitated using the Marcq St Hilaire method of deriving intercepts as the difference between the pre-computed altitudes and my observed altitudes. The subsequent plotting was a small price to pay for avoiding the tedium of manual spherical trigonometry calculations with their greater opportunities for error.

Of the five star observations planned, perhaps one or two would be obscured or not work out satisfactorily, but more often than not, a reasonably accurate 
position could be obtained and plotted 'on the chart' within 25-30 minutes from start to finish.

3.2. Time Considerations. A point affecting accuracy and not yet mentioned was the ability to count seconds (i.e. 'And one, and two ..." etc) when striding in from the bridge wing to the chronometers to record the time of the specific star sight, deducting those seconds counted from the chronometer time as read.

In my view, the best estimate of a vessel's progress was from morning sights to morning sights. While this was not an exact 24 hour period, all seagoing navigators became proficient with the decimalisation of the hour $(6 \min =1 / 10$ or $0 \cdot 10$ of an hour). Similarly it was a joy to sail on vessels that averaged say 15 knots, thus 360 miles for the DR days run. But no matter what the speed or distance, Norie's Tables could solve the problem via the well-thumbed 'time, speed and distance' table, handily placed near the front of the book.

Morning star observations to me meant the start to a new day, tea and toast brought to the bridge as the Sun was rising and a quiet period before the ship started to come to life shortly before 0800 . All was right with the world!

One of the routine duties of the 2nd Mate, as Navigating Officer, was the responsibility for the two chronometers (normally annotated A and B) and sited in a green baize-lined recess under the chart table where they could be viewed through a glass panel flush with the table. Clearly, I served on better found ships than John, whose tankers were supplied with only one chronometer (I wonder how they coped if it failed?). My two chronometers were dutifully wound at the same time every day and, daily, the opportunity was taken to check them with the Greenwich time signal, kindly supplied by 'Sparks' from his adjacent Radio Room or via a loudspeaker if not adjacent. Any error, plus or minus, was duly entered in the Chronometer Book.

Looking back, we had record books for everything. Compass Error Book, Chronometer Book, Change of Clocks Book, all of which would be initialled and countersigned as read by either the Chief Mate or Master. I'm sure the all-important and self-explanatory Night Order Book still exists in some form or another.

This daily chronometer routine was interrupted while in port and I can only recall once when both chronometers stopped in port when their springs had run down after 48 hours; simply a case of forgetfulness, irregular port routine having taken priority. With the connivance of 'Sparks' while the 'Old Man' was ashore, both chronometers were set to 1200 and started on the time signal by a brief 'clockwise and back' rotational movement. Fortunately, my oversight was not spotted, the subsequent error being similar to previous observations.

The fact that John records a similar experience when in port suggests that it was not uncommon for 2nd Mates to forget to wind their chronometers in port, although one should be cautious about deriving a generalisation from a sample of two.

3.3. Hybrid Observations. Crossing the Bay of Biscay was still an ocean passage, although when nearing the UK I was, as 2nd Mate, keen to avoid the daily routine of morning and noon Sun sights. However, as noon always seemed to occur half way across the Bay, I often used a Mer Alt crossed with bearings from the Consol stations at Plonéis in Brittany or Seville or Lugo in Spain.

The interpretation of Consol bearings was an art that no two persons seemed to agree upon! The requirement was to count the dots and dashes in a radio signal and, where these merged into a continuous 'null', divide this null period into equal parts to the number of dots and dashes so that together they totalled 60. With these figures, 
one entered tables (in a volume of the Admiralty List of Radio Signals) and the result was a bearing of the Consol station. Admiralty charts overprinted with great circle bearings corresponding to different dot and dash counts from Consol stations were also available and made the plotting much simpler.

Consol bearings were also available from stations at Bushmills in Northern Ireland and Stavanger in Norway. Consol bearings were available at much longer range than Radio Direction Finding (RDF) bearings and we considered them to be more reliable. Achieving a cross from a Consol bearing and an astro position line was a satisfying experience, although looked on with suspicion by the old school of shipmasters. For more detail with Consol, see Sven Gyldén's experience (Kemp et al., 2008, Section 8.4).

Proceeding on a north easterly heading across the Bay of Biscay, one had the warning of the 100 fathom line before altering course off Ushant (which was often shrouded in mist or fog). In other parts of the world it was also possible, on occasion, to cross an astro position line with a depth contour or even with a bearing of a distant landmark, in order to define a fix.

Whatever the exact circumstances, we felt there was a kind of magic in being able to find our position on the Earth by observing the Sun, nine million miles away, or a star many light years distant.

\section{CATHERINE HOHENKERK.}

4.1. The Nautical Almanac. In the late 1970s I joined HM Nautical Almanac Office (HMNAO), which was then part of the Royal Greenwich Observatory, when my main task was running and checking the programs that produced the data for The Nautical Almanac (NA). Today HMNAO is part of the UK Hydrographic Office (UKHO), and the NA is still our primary publication. Now as then (in fact since 1958) the NA (HMNAO and USNO, 1958-2013) is a joint publication with the Nautical Almanac Office of the US Naval Observatory (USNO). It is also still supplied, under various terms, to many countries and commercial almanac producers around the world.

The object of the NA is, and has been since the very first edition in 1767, "To provide, in a convenient form, the data required for the practice of astronomical navigation". It has not been a static publication. However, the format of the main tabular pages has hardly changed over the last 50-plus years. In 1989 additional sections were added. An algorithm for use with calculators or personal computers, based on the least-squares solution of the Marcq St Hilaire method of intercepts was provided. At the same time, at the opposite end of the spectrum, USNO produced some Concise Sight Reduction Tables and the associated procedures for finding the calculated altitude and azimuth, where only pencil and paper are required were also included.

Nowadays, the non-changing style and format of the layout is important as this helps to ensure that navigators (who may only use the publication infrequently, since astro navigation has become a backup procedure) are familiar with where to look up the data they need and how to reduce their sights in an emergency.

4.2. Rapid Sight Reduction Tables. Another long-running publication, although for not as long as the NA, are the 'Sight Reduction Tables'. These are pre-computed tables of altitude and azimuth that solve the PZX spherical triangle that is required when reducing sextant observations. The particular volume mentioned by Brian in 
Section 3.1 'Sight Reduction Tables for Air Navigation [AP3270/Pub.No.249], Volume 1, Selected Stars, Epoch 1965.0' (HMSO, 1962) is part of the 3-volume set that was originally designed for air navigation, as its title and designation 'AP' indicates. Volume 1 is published every five years and gives the calculated altitude and azimuth of the best selection of seven stars to observe, for all latitudes and local hour angles. This volume is the most popular of the volumes. Its ease of use was promulgated not only by air navigators who were also sea navigators but also by the book Celestial Navigation for Yachtsmen (Blewitt, 1950).

In the early 2000s I re-wrote the explanation, recognising that most of the users were now marine navigators. The 3-volume set was therefore re-titled Rapid Sight Reduction Tables for Navigation (HMNAO, 2010) and the designation 'AP3270/NP 303' was maintained, as many mariners were still familiar with the moniker 'AP3270, Air Tables'.

Since the 2000.0 edition, the UK [AP 3270/NP 303] and US [Pub.No. 249] volumes (HMSO, 1962) have been produced and published independently, although cooperation and checking are still maintained. I am currently nearing completion of the latest volume for epoch 2015.0, which is also a joint publication with USNO, and is to be published later this year.

4.3. Approximating Ephemerides. At the beginning of the 1970s, work was done on using Chebyshev polynomials to represent the ephemerides of the navigational planets Venus, Mars, Jupiter and Saturn (Sinclair, 1971). Chebyshev polynomials are orthogonal polynomials with properties that are very useful for approximating functions to a given accuracy. Thus software was developed to use Chebyshev polynomials to represent various coordinates such as Right Ascension (RA), Declination (Dec), Greenwich Hour Angle (GHA), Semi-Diameter (SD), and Horizontal Parallax (HP) of the various celestial objects.

The availability of small programmable calculators led to requests that extensive tabulations should be supplemented by algorithms, that would allow for direct evaluation at the required instant, without the use of tedious interpolation tables. This resulted in developing 'economised' polynomial coefficients (Sinclair, 1975a; 1975b). This involves approximating the function (e.g. RA or Dec) using a Chebyshev series and then re-arranging the coefficients for output so that the user is presented with an equivalent polynomial series. Users, who are probably not conversant with Chebyshev polynomials, will find polynomials much easier to use and implement.

The goal is to make it as straightforward as possible for the user. Thus having decided on the accuracy required for the particular function (e.g. 0.01 minutes of arc), the 'art' was deciding on the period over which the coefficients should be valid (e.g. 1 day, 1 month, 100 days, 1 year, 5 years) and the order of the polynomials. Of course these factors are all inter-related.

During the 1980s other avenues of approximations were tried out using programmable calculators and the emerging Personal Computers (PC). In order to provide the navigator with algorithms for all celestial objects, not just the navigational planets, other strategies were tried. For the Moon, due to its movement, it was found efficient to provide users, particular those who were now using PCs rather than calculators, with monthly Chebyshev coefficients for ecliptic coordinates, together with an algorithm to transform to GHA and Dec. The use of ecliptic coordinates reduced the number of terms needed and the extra calculation to transform to the coordinates required is simple to program. 


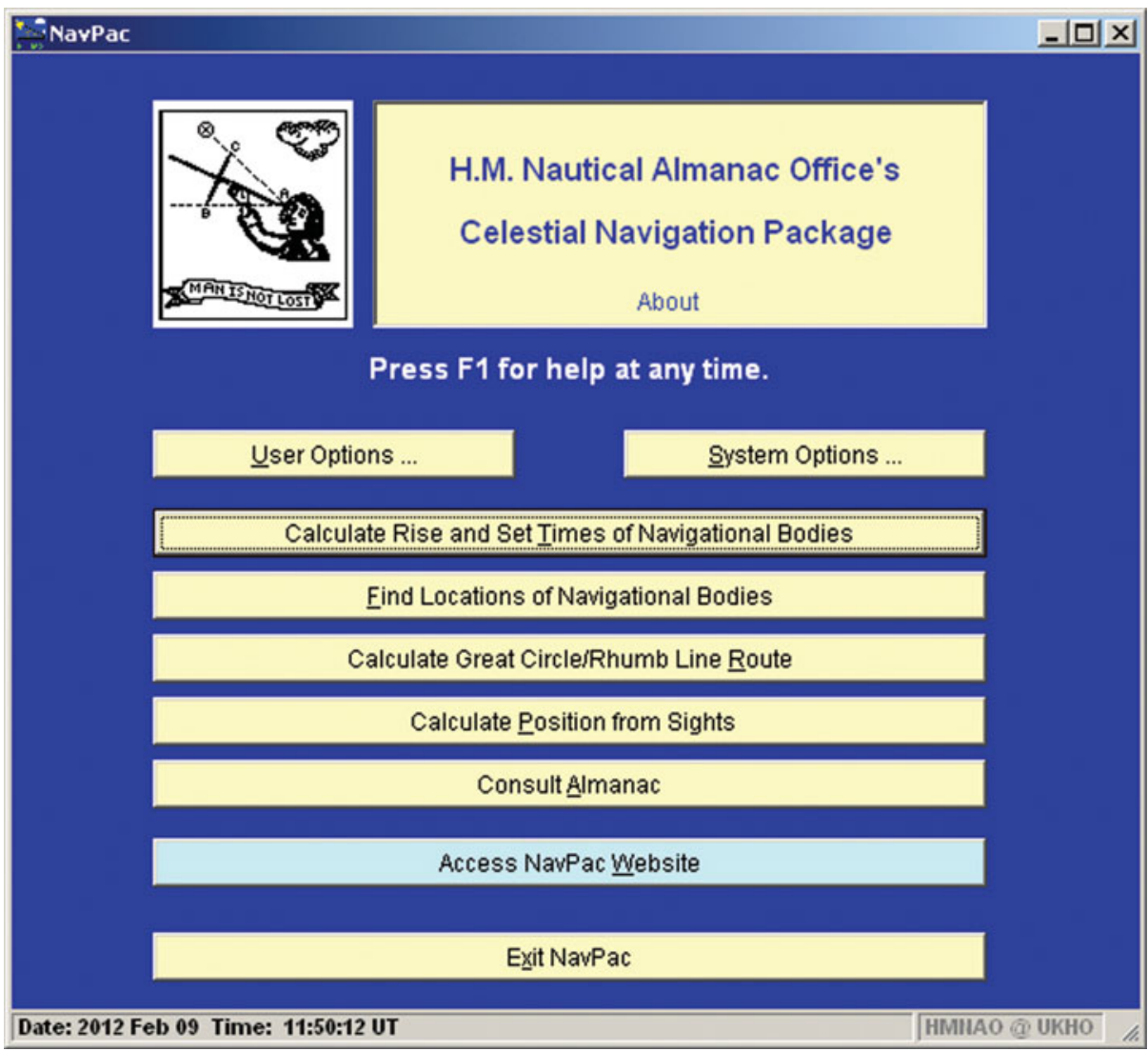

Figure 4. NavPac's main screen showing the options. Apart from the user and system options the five main functions are (1) RiseSet: times of rise and set including times for azimuth checks, (2) Findit: altitudes and azimuths of objects, (3) Finder: great circle or rhumb line routes, (4) Sights: reduction of sights and (5) an Almanac function.

For the stars, a least-squares solution of a mixed function type of approximation was found to be best (Hohenkerk and Yallop, 1985). This function is linear in time with various sine and cosine terms and represents the dynamics (i.e. the effect of proper motion of the stars, aberration, precession and nutation). Depending on the accuracy and length of period of validity that is needed (i.e. 1 year, 5 years) different numbers of terms may be included.

4.4. NavPac. 'NavPac and Compact Data, 2011-2015' (Hohenkerk and Yallop, 2010), which is generally known by its short title 'NavPac' (see Figure 4), is the UKHO/HMNAO's PC software that was first published in the 1990s (Yallop and Hohenkerk, 1995). It enables navigators to find their position at sea from observations made with a marine sextant. The current version of the software is valid from 1986 to 2015 (see http://astro.ukho.gov.uk/nao/navpac/). It has been adopted by the Royal Navy as their primary method of sight-reduction to calculate astro navigation positions; their use of NavPac is described in the Admiralty Manual of Navigation (Royal Navy, 2011). 


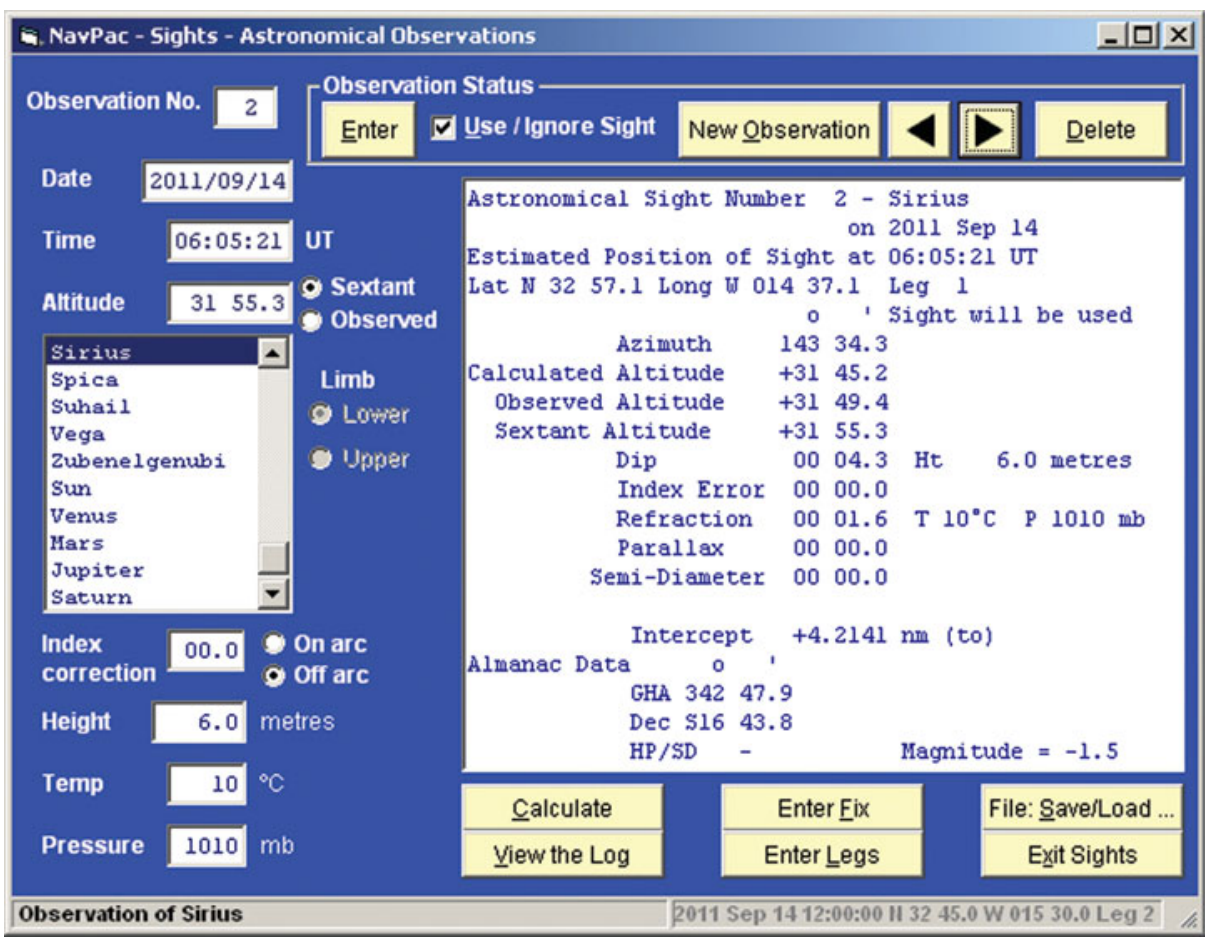

Figure 5. NavPac's Sights - Astronomical Observations screen, showing an observation of Sirius together with its sight reduction. All the options are indicated via the yellow-button boxes.

At the heart of NavPac are the ephemerides. The work on using various functions to approximate the positions of the required celestial objects, to a consistent precision, forms the basis of the ephemerides used. Thus NavPac brings together the monthly economised polynomials for the GHA-UT and the Dec for the Sun, planets, approximations for the Moon and the 57 navigational stars (where UT stands for Universal Time and more precisely means UT1, which is related to the rotation of the Earth). It uses the least-squares approach to the Marcq St Hilaire method for finding position, which was first introduced in the NA in 1989.

The goal of the NavPac software is not only to take the tedium out of astro navigation, but also to provide a learning tool through the 'sight-reduction' steps; an illustration is shown in Figure 5. Here the example is an observation of Sirius made on 14 September 2011 (shown as 2011/09/14 in Figure 5) at 06:05:21 UT, when the sextant altitude was $31^{\circ} 55^{\prime} .3$. Down the left side of this 'Astronomical Observations' menu, all the input parameters may be specified. These include index error correction, height of eye as well as the meteorological conditions, temperature and pressure needed for calculating refraction. If the celestial object observed was the Sun or Moon, then the upper or lower limb must be specified. The large box on the right contains the 'sight-reduction' for the particular observation. In the bottom-left of the box, using the date, time and object, the almanac data is displayed. NavPac will have already made an initial estimate of the position at the time of observation using the initial DR position, speed and course (supplied earlier via the Enter Fix and Enter 


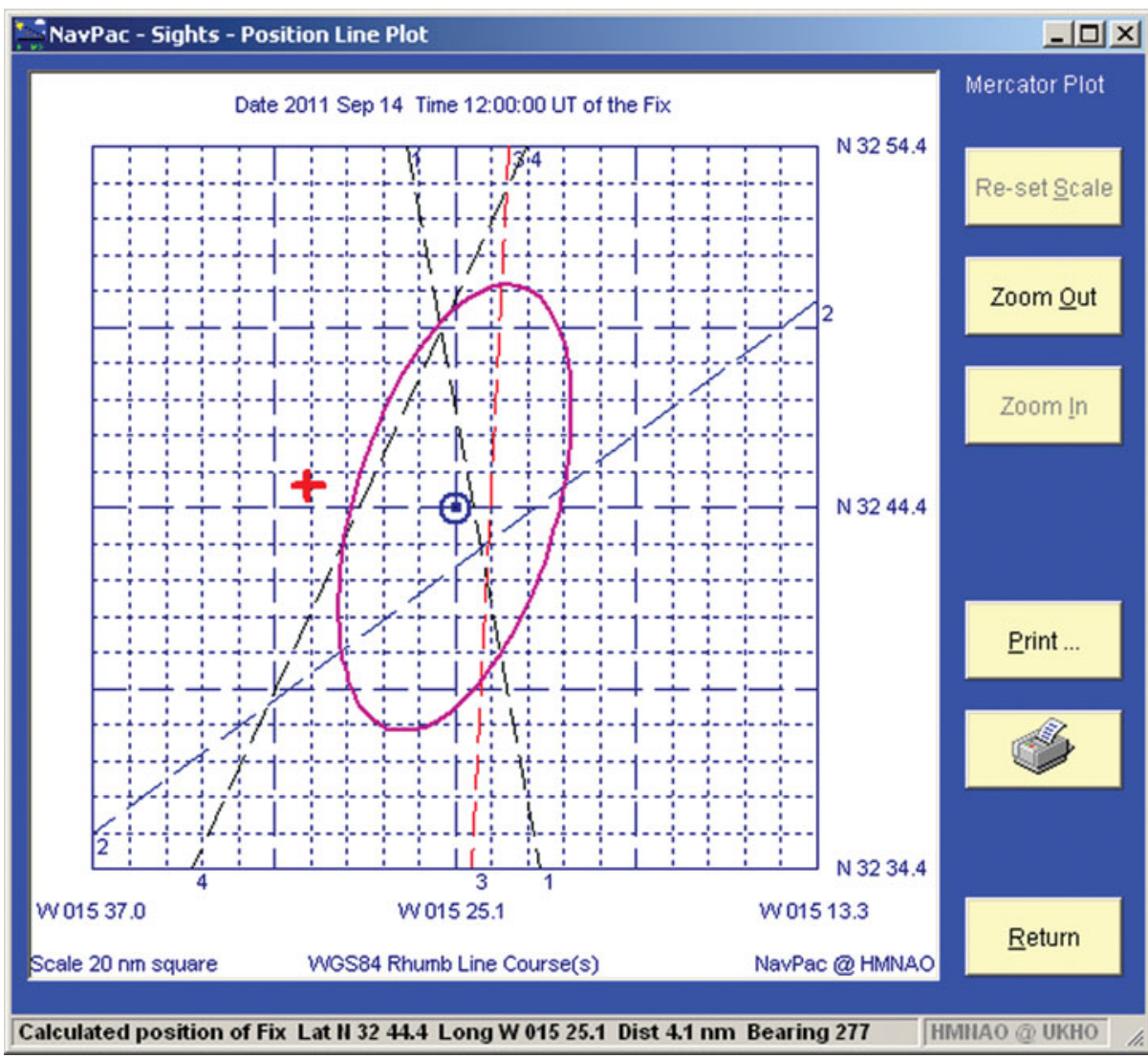

Figure 6. NavPac's Sights-Position Line Plot, showing at the centre of the plot the calculated position of the Fix. The initial DR position is shown by the red cross. The status bar reports the calculated position and the distance and bearing to the DR. The four position lines are dashed as the times of the observations are more than 15 minutes away from the time of the Fix. The magenta ellipse is the $95 \%$ confidence ellipse.

Legs options) and this information is summarised in the status bar at the bottom of the screen.

Using all this data, NavPac produces the calculated altitude and azimuth (in this case, of Sirius). Finally, all the corrections required are calculated and the intercept is given, indicating if it is 'from' (-) or, as in this case, 'to' (+). The intercept is printed here to four decimal places of a nautical mile, which is done to help navigators doing their own programming as rounding is only carried out when numbers are output.

Thus, whatever celestial object is observed, no additional correction tables are needed (i.e altitude correction tables for the Sun, stars and planets; altitude correction tables for the Moon that involve HP; or any additional refraction corrections). However, the process with all the corrections is shown, allowing the navigator to be reminded of the various steps.

Figure 6 shows a plot of four position lines, including the observation of Sirius. This is not the result of traditional plotting of the calculated intercepts from the DR. These 
intercepts are the result of the least-squares solution, using the timed observations, duly reduced, the initial DR (which due to the least-squares method could be a wild guess) together with the speed and course of the vessel during the observations. The example in Figure 6 comes with the NavPac software, as a teaching aid.

NavPac allows mariners to concentrate on acquiring the skills necessary to make accurate observations without the drudgery of looking up all those tables correctly, only to find they have made a slip. Today, such mistakes become obvious since navigators usually know their GNSS position anyway! However, no-one can find their position using astro navigation unless they can take accurate sights. All that is needed is to identify the star or planet being observed, know how to use the sextant correctly and record not only the sextant altitude, but also the time of the observation in UT1. In varying weather conditions with clouds scudding across the sky, the sea horizon becoming invisible or the Sun rising puts pressure on the navigator to make the several observations needed to get a good fix. That is to say nothing about the sea state. I once witnessed people of varying experience taking Sun sights in the Bay of Biscay on a lovely calm day. Needless to say, one of the Royal Navy's top navigators was within $0 \cdot 4$ nautical miles, while the trainee was 4 nautical miles from the GPS position! To use a sextant effectively requires practice.

NavPac is a tool that helps provide navigators with all the astronomical data they require, not just 'sight reduction' as described above. The main options are given on the opening menu (see Figure 4). The other tools include almanac type data, the times of rise and set, civil and nautical twilight, times for azimuth checks, great circle and rhumb line sailings. The navigator may obtain an altitude-azimuth plot of all the objects visible in order to plan their observations between civil and nautical twilight. This plot indicates the best seven stars that would be given using AP3270/NP303 (HMNAO, 2010), and the choice of objects may be saved and re-used in the sight reduction later.

4.5. Astronomical Data for Navigation. If the international community decides to drop leap seconds so that Coordinated Universal Time (UTC) and UT1 do not lie within the 0.9 seconds which the current standard requires, then UKHO/HMNAO/ USNO will need to consider how to provide almanac data that is easy for the mariner to use.

The challenge ahead is to continue to provide data in the most suitable form for the practice of astro navigation at sea. This must encompass two sides of the same coin. On the one hand, in times of emergency, when perhaps, a coronal mass ejection from the Sun or a near-Earth object or space debris has damaged satellite systems and renders modern technology unavailable (i.e. communications, GNSS and the internet/ world-wide web), traditional solutions become crucial. On the other hand, providing solutions for navigators who want modern technology tools (i.e. computers, 'apps' and the world-wide web) to simplify the computations and so greatly improve the accuracy as well as making astro navigation straightforward.

5. CONCLUSIONS. The partnership of a navigator and his sextant was a lifetime affair (John and Brian still have theirs). A serviceable modern sextant cost rather more than a month's wages. It was as beautiful as it was precise and one understood exactly how it worked. It is a shame that there can nowadays be no such mystique between an instrument in a plastic box containing unknowable electronic 
algorithms and the pusher of its buttons. The box will, in any case, be obsolescent after a year or two as Moore's Law continues its implacable advance in computer technology. There is neither the time nor the motivation to develop a meaningful relationship.

Practical navigators, like Brian and John, looked upon The Nautical Almanac (NA) with awe. We knew just enough about the apparent movement of celestial bodies across the sky to realise the scale of the effort required from people like Catherine, to predict those movements for years ahead and to reduce the findings to a form that we dutiful, but not necessarily very bright, sailors would be able to use.

Clearly, times and attitudes change and astro navigation has long lost its central role in a marine navigator's repertoire, despite its immunity to GNSS jamming and spoofing. The world, no less than the sailor, is becoming dangerously dependent on GNSS with its better availability and much superior accuracy, but also greater vulnerabilities. A wise man ashore keeps a box of candles at the back of his useful bits and pieces cupboard. For similar reasons, a prudent mariner keeps a sextant under his bunk, an almanac in his bookcase and the knowledge of how to use them in his head.

Fortunately for the cause of common sense, Catherine and her colleagues will continue to produce the NA in both hard copy and electronic form for the foreseeable future. As for John and Brian, our sextant boxes gather dust and the tables of precomputed altitudes that still reside in Brian's bookcase are forty years out of date, but the satisfaction derived from years of astro navigation across the world's oceans still remains with us. "Yesterday is the playground of all men's hearts-especially those of sailormen” (Ritchie, 1915).

\section{REFERENCES}

Blewitt, M. (1950). Celestial Navigation for Yachtsmen (12 ${ }^{\text {th }}$ edition). A \& C Black.

HMNAO and USNO. (1958-2013). The Nautical Almanac-NP314. United Kingdom Hydrographic Office.

HMNAO, (2010). Rapid Sight Reduction Tables for Navigation-AP3270/NP303. United Kingdom Hydrographic Office.

HMSO, (1962). Sight Reduction Tables for Air Navigation-AP3270, Volume 1, Selected Stars, Epoch 1965.0. HM Stationery Office.

Hohenkerk, C. Y. and Yallop, B. D. (1985). Coefficients for calculating the GHA and Dec of Stars. NAO Technical Note 62.

Hohenkerk, C. Y. and Yallop, B. D. (2010). NavPac and Compact Data, 2011-2015-DP 330. United Kingdom Hydrographic Office.

Kemp, J., Cockcroft, N., Gyldén, S., Iijima, Y., Koburger, C., Lyon, P., Page, D., Thirslund, S. (2008). The Use of Soundings in Navigation in the Mid-20 ${ }^{\text {th }}$ Century. The Journal of Navigation 61, 629-642.

Lecky, S. T. S., Allingham, W. (1920). Wrinkles in Practical Navigation, 20th edition. George Philip \& Sons Ltd.

Ritchie, L. A. (1915). A Tall Ship, on Other Naval Occasions. Cassel \& Co Ltd.

Royal Navy, (2011). Admiralty Manual of Navigation, Volume 2, Astro Navigation. The Nautical Institute. Sinclair, A. T. (1971). The Representation of Planetary Ephemerides for Use in the Automatic Reduction of Navigational Sights. NAO Technical Note 26.

Sinclair, A. T. (1975a). The Tabulation of Monthly Sets of Polynomial Coefficients for Astronomical Data in the Star Almanac for Land Surveyors. NAO Technical Note 37.

Sinclair, A.T., (1975b). Survey Review, 23, No. 178, 151-154.

Yallop, B. D. and Hohenkerk, C. Y. (1995). Compact Data for Navigation and Astronomy, 1996-2000. HMSO. 